Assessing how closely postgraduate translation programmes fit the reality of professional practice: a case study of the Spanish context

Ana Muñoz-Miquel

Translation and Communication Department, Universitat Jaume I, Castelló de la Plana, Spain

munoza@uji.es 


\title{
Assessing how closely postgraduate translation programmes fit the reality of professional practice: a case study of the Spanish context
}

\author{
Ana Muñoz-Miquel \\ Translation and Communication Department, Universitat Jaume I, Castelló de la Plana, \\ Spain
}

This paper presents the results of an empirical descriptive and contrastive study designed to assess how closely postgraduate translation programmes fit the reality of professional practice. Focusing on medical translation, the case study analyses the convergences and divergences between the competences that professional medical translators deploy in their work and highlight as being essential and those that students are expected to acquire in postgraduate courses in which medical translation is taught.

Two empirical studies were conducted. The first study focused on a socioprofessional perspective: 167 English-to-Spanish medical translators were surveyed to obtain information about their profiles and their opinions on the competences needed for medical translation. The second study focused on an academic perspective: the syllabuses of postgraduate courses in which medical translation is taught in Spain were analysed to determine the competences students are expected to acquire. The results of these two studies, which are analysed, compared and discussed, show that there are a significant number of convergences, but also some divergences, between the university courses and the professional practice. These raise interesting questions which need to be taken into account when designing, planning and improving existing and new postgraduate courses.

Keywords: competences, gap between the profession and academia, medical translation, postgraduate programmes, professional translators.

\section{Introduction}

Bridging the gap between university training and professional practice is one of the main goals of the current framework for Higher Education in Europe. All undergraduate and 
postgraduate programmes have to be based on acquiring competences and must take into account existing professional profiles in the job market (González and Wagenaar 2003; Yániz and Villardón 2006; Hurtado 2007; Calvo 2010). This framework, which has been called competence-based training, 'takes professional practice into account, with the competences to be acquired on a given programme being defined on the basis of a description of the corresponding professional profile' (Galán-Mañas and Hurtado 2015, $63)$.

Professional profile is defined in translation pedagogy as the concept that 'explains the main roles and functions that a profession fulfils, as well as the most common tasks in which those roles and functions are embodied' (Yániz and Villardón 2006, 18). By determining professional profiles using the professionals themselves as a source of information, it is possible to guide curriculum planning, since the functions and tasks carried out by professionals are those that allow us to identify the competences required to perform them (Yañiz and Villardón 2006, 18).

According to Calvo (2010, 150), this link between competences and professional profiles is determined by a 'cyclical conception' of the relationship between society/job market and training: after analysing the job market, the next step is to identify the professional profiles required by the market, which are then translated into a series of competences to be acquired by students. The cyclical process ends, in turn, by assessing how closely training programmes fit the competences identified in the job market, because 'programmes need constant feedback in order to help them improve' (Kelly $2005,145)$.

Translator training had already embraced the importance of competences (i.e. the capacities, knowledge and skills possessed by professional translators [Kelly 2002, 14]) in designing, implementing and assessing training programmes before these were prescribed by the Bologna process (Kelly 2005, 2007; Calvo 2011). However, the creation of the European Higher Education Area (EHEA), with its ultimate goal of enhancing education by taking professional practice into account, has intensified the need for empirical studies aimed at identifying the competences translators actually possess and establishing what they are required to do in their professional practice (Vigier 2010; Sachinis 2011; Cerezo 2012; Li 2012; Toudic 2012; Muñoz-Miquel 2014, 2016a). But do the competences taught in current translator training programmes match those that professional translators actually use or consider important when practising their profession? Are they representative of what is being done in real professional practice? 
This paper presents the results of an empirical descriptive and contrastive case study whose aim was to assess how closely postgraduate translator training programmes, which are those that develop students' professional specialisation, fit the reality of professional practice. This study, which focuses specifically on medical translation, uses the notion of competence as an instrument to assess whether current programmes provide the competences that medical translators deploy in their work and consider essential when exercising their profession.

In translator training, the concept of assessment has traditionally been seen in the light of gauging to what extent students have acquired the competences as set out in the learning objectives (Kelly 2005; Galán-Mañas and Hurtado 2015). However, Martínez and Hurtado (2001) have identified three possible settings for assessment: 1) assessment of published translations, 2) assessment in professional practice, and 3) assessment in translation teaching, which includes assessing both the students' competences and the training programmes themselves. Our paper approaches assessment from the perspective of the third of these settings.

As mentioned earlier, the study presented in this paper focuses on medical translation. This specialisation is one of the most fertile in terms of job prospects and career development (Muñoz-Miquel 2014). However, it is still relatively young from an academic and disciplinary point of view, and there is a lack of studies that deal with professional and training issues in this area. As far as I am aware, very little empirical research has been conducted on the profile and competences of medical translators (with the exceptions of the studies by O'Neill 1998; Jensen and Zethsen 2012; Muñoz-Miquel 2014, 2016a; and Martínez 2016). Most studies appear to be based on anecdotal evidence or personal experience. Moreover, there are very few studies on medical translator training programmes to be found in the literature (the works by Lázaro 2014 and MuñozMiquel 2016b are two exceptions). The main goal of this paper, therefore, is to contribute to bridging that gap by conducting two empirical studies, one focusing on a socioprofessional perspective and one on an academic perspective, to analyse the convergences and divergences between the competences that medical translators deploy in their work and consider essential and those that students are expected to acquire in postgraduate courses in which medical translation is taught.

The paper is structured as follows: Section 2 explains the materials and methods used; Section 3 describes the results obtained in the two empirical studies; Section 4 analyses the convergences and divergences between the socio-professional and academic 
perspectives, and Section 5 presents the main conclusions and suggests some future lines of research.

\section{Materials and methods}

In the study on the socio-professional perspective, medical translators were surveyed to obtain information about their profiles and the competences needed to practice their profession. In the study on the academic perspective, the syllabuses of the postgraduate courses in which medical translation is taught were analysed to determine which competences students are expected to acquire. In the following sub-sections, the methods used in each empirical study are explained.

\subsection{Empirical study 1: Socio-professional perspective}

\subsubsection{Study population}

The medical translators surveyed had to meet two criteria: (1) practising medical translation, either exclusively or as one of their specialisms; (2) working in the EnglishSpanish language pair.

An ad hoc census of potential respondents had to be created, since there are no official figures available on the number of medical translators in Spain or in other Spanish-speaking countries. To carry out this census, membership lists of translators' associations and directories were accessed, such as Tremédica (the International Association of Medical Translators and Writers), the Medical \& Pharmaceutical Network of the Institute of Translation and Interpreting, Asetrad (Spanish Association of Translators, Editors and Interpreters), APTIC (Association of Professional Translators and Interpreters of Catalonia) and Proz. The census consisted of 451 translators.

\subsubsection{Data collection instrument}

The data collection instrument was an online questionnaire designed using the LimeSurvey system. The design was based on the results of a previous exploratory qualitative study, in which 12 medical translators with different professional (freelance or in-house) and academic profiles were interviewed (Muñoz-Miquel 2014). Academic profiles were characterised as 'translators with a linguistic background' (TLBs) or 
'translators with a scientific-medical background' (TSBs).

The questionnaire consisted of 47 questions, the majority of which were closed. These were grouped into three blocks:

- Academic and socio-professional profile, which included questions about training received, clients, genres and topics translated, difficulties encountered, resources used, years of experience, and tasks performed, among others.

- Competences, where respondents had to assess the importance of a given list of competences on a 1-to-5 Likert scale. To this end, we developed a framework of competences based on: (1) the results of the interviews conducted with medical translators in the qualitative exploratory study (Muñoz-Miquel 2014); (2) literature reviews on translation competence models (Kelly 2002, 2005; PACTE 2003; Hurtado 2007); and (3) the works in which medical translator competences are dealt with either directly or indirectly (Rouleau 1994; Wakabayashi 1996; Félix and Ortega 1998; Fischbach 1998; O’Neill 1998; Balliu 2001; Lee-Jahnke 2005; Mayor 2006; Montalt and Gonzaléz 2007; Jensen and Zethsen 2012).

- Opinions about medical translator training, which included some questions to discover their views on this topic.

Due to space constraints, this paper mainly focuses on the results with respect to respondents' assessment of the competences needed to practise medical translation (second block of questions). It also focuses on those aspects of the socio-professional profile (first block of questions) that can either be translated into competences (e.g. tasks performed or difficulties addressed) or serve to refine certain competences (e.g. genres translated could help determine which genres should be taught at universities) according to the cyclical conception of the relationship between society/job market and training addressed in Section 1. Translators' answers to some of the questions on medical translator training are also presented.

\subsubsection{Response rate and data analysis instrument}

A total of 167 valid responses ${ }^{1}$ were received, which represents a response rate of $37 \%$ of the census of potential respondents. The answers were analysed with the IBM SPSS Statistics software package. The SPSS tools used were those employed for descriptive statistics: frequencies, descriptives and contingency tables. Some inferential statistical 
tests (ANOVA and Chi-squared tests) were also carry out when we compared the answers provided by TLBs and TSBs (see Muñoz-Miquel [forthcoming] for further details).

\subsection{Empirical study 2: Academic perspective}

\subsubsection{Study population and documents analysed}

The study focused on the curricula of the postgraduate courses in which English-toSpanish medical translation is taught in Spain. Since the extent to which courses are dedicated to medical translation varies substantially, the analysis included two types of programmes:

- Those that specialise in medical translation; i.e. those dedicated exclusively to this specialisation.

- Those that are non-specialised; i.e. those in which medical translation is taught together with other areas of specialisation.

To determine which programmes met these criteria, the first step was to compile a list of all the translation postgraduate programmes offered during the academic year 2015-2016, according to the Spanish Ministry of Education, Culture and Sport. Courses specifically oriented towards interpreting, research or other areas of specialisation were excluded. The programmes analysed are shown in Table 2 (see Section 3.2).

We also analysed the syllabuses of the medical translation course units included in these programmes. A course syllabus is a "public document containing a detailed plan of the course units in a programme based on EHEA principles' (Fortea 2007, unnumbered). As this is the method used by trainers to embody curriculum design and planning, it constitutes the ideal instrument for determining the competences that students are expected to acquire. The sections of course syllabuses analysed were not only those directly related to competences (i.e. competences themselves and the associated teaching objectives/learning outcomes), but also others from which one can infer the competences to be acquired, that is, content, teaching and learning methods, and especially assessment (Kelly 2005; Hurtado 2007), since 'investigating the ways universities assess trainee translators can reveal $[. .$.$] the competencies that are considered necessary in a translator'$ (Huertas Barros and Vine 2015, 370). 


\subsubsection{Data analysis method}

The method used to analyse the competences was content analysis. Taking the list of competences used in the survey of medical translators (see Section 2.1.2) as a reference framework, the information given in the course syllabuses was 'translated' onto this framework of competences. ${ }^{2}$ This made it possible to determine which competences in the framework were mentioned in the course syllabuses. The number of programmes that mentioned each competence in at least one medical translation course unit in their curricula was subsequently quantified.

\section{Results}

This section explains the results obtained in the two empirical studies.

\subsection{Empirical study 1: Socio-professional perspective}

\subsubsection{Socio-demographic data}

The sample was made up of $70 \%$ women and $30 \%$ men, with a mean age of 43 . The predominant nationality was Spanish (67\%) with the rest coming from Latin American countries (28\%), predominantly Argentina; the United States (3\%); and other European countries (2\%), i.e. United Kingdom, Germany and Italy.

In terms of academic profile, the majority (52\%) were TLBs; i.e. they had studied Translation and Interpreting, or Philology. A third (33\%) were TSBs (i.e. they had studied Medicine, Biology, Pharmacy or Veterinary Science); 3\% had both a linguistic and a scientific background; and $7 \%$ reported other situations, such as having studied other degrees or having no university qualifications. Over half the respondents (56\%) stated that they had completed a master's degree or a doctorate.

\subsubsection{Socio-professional profile ${ }^{3}$}

3.1.2.1. Tasks performed. In addition to translation itself, $76 \%$ of respondents reviewed or proofread translations. The next most common task (29\%) was terminology and document management (i.e. creating style guides, producing glossaries, etc.). Respondents also indicated that they were in charge of directing processes for selecting translators $(20 \%)$ and that they managed projects $(18 \%)$. A considerable percentage 
(17\%) adapted specialised texts for patients and the general public. Finally, $7 \%$ wrote original medical texts.

The answers to the optional question about what other tasks they performed included the following: transforming specialised genres into others intended also for specialists (e.g. transforming research papers into oral communications); adapting documents about a medical product for the Spanish market; post-editing translated documents.

3.1.2.2. Genres and topics translated. Respondents indicated that they translated a wide range of genres and topics, predominantly those from pharmaceutical and research sectors.

Translators were provided with a list of 37 different genres. The most common genres were clinical trial protocols and informed consent documents, both of which were translated by $47 \%$ of the respondents. These were followed by fact sheets for patients $(38 \%)$. The next items, translated by between $24 \%$ and $33 \%$ of the respondents, were protocol amendments, instruction manuals for medical instruments and healthcare devices, research papers, abstracts, quality-of-life questionnaires, and summaries of product characteristics. The least frequently translated genres (between $2 \%$ and $6 \%$ ) were anatomical atlases, medical reports and standard operating procedures.

Translators were provided with a list of 31 different topics. The most commonly translated topics (60\% of the respondents) were those related to pharmacology and the pharmaceutical industry. This was followed by translations related to medical instruments and healthcare devices (43\%), advertising healthcare products (33\%), oncology (31\%), general medicine (30\%), epidemiology and public health (23\%), and cardiology (23\%). The least frequently translated topics (between $1 \%$ and $5 \%$ ) were homeopathy, natural medicine, paediatrics and intensive care.

3.1.2.3. Main difficulties encountered. In this question translators had to assess the degree of difficulty (from 1, 'I never find it difficult', to 5, 'I always find it difficult') of some aspects of medical translation. Translating the cultural asymmetries that arise from differences in healthcare systems and from different conceptions of health and disease was the aspect that presented the greatest difficulties (mean of 2.66), followed by finding reliable documentary resources (2.28), and choosing the terminological equivalent best suited to the context (2.22). Understanding highly specialised content (2.08), and using 
the phraseology employed by specialists (1.97) were the least frequent difficulties encountered.

The data were filtered by the type of respondent i.e. TLBs or TSBs to see whether difficulties were perceived differently according to the academic profile. ${ }^{4}$ The results showed that TLBs found all the problems (except the translation of cultural asymmetries) significantly more difficult to solve than TSBs, especially understanding specialised concepts $(p$-value $=.001)$ and using the phraseology employed by target readers $(p$ value $=.002)$. TSBs, however, reported encountering more difficulties when translating cultural asymmetries $(p$-value $=.262)$.

The 51 answers to the optional question also showed some other difficulties, such as dealing with poor wording and lack of clarity in the source texts, grasping the meaning of abbreviations and acronyms, respecting customer preferences, and translating topics that are developing very quickly (e.g. molecular biology or genetics).

3.1.2.4. Additional training received. Nearly all the respondents (92\%) had found themselves having to undertake further training to make up for shortcomings when translating medical texts. Self-directed training was the option chosen by the majority $(60 \%)$, followed by specific non-university medical translation courses (49\%). Twentysix per cent had done other university courses, which may account for the high percentage of translators with postgraduate qualifications (see Section 3.1.1). Finally, 8\% claimed that the degree that they had studied had been enough to enable them to translate medical texts.

As regards self-directed training, the main reason why translators taught themselves was to acquire the conceptual knowledge required to translate the medical topics that made up most of the volume of work they received (44\%). The second most cited reason $(31 \%)$ was learning to use computer-assisted translation (CAT) or other information and communication technology (ICT) tools. This was followed by acquiring basic medical knowledge (28\%), improving one's mother tongue $(22 \%)$ and learning/improving foreign languages (17\%).

As in the question concerning the main difficulties encountered in medical translation (see Section 3.1.2.3), differences emerged between TLBs and TSBs with respect to their training needs. On the one hand, TLBs perceived that their main weaknesses related to conceptual issues, since they needed more additional self-directed training of this kind than TSBs did ( $p$-value $=.000)$. On the other hand, TSBs seemed to 
have more limitations when it came to mastering their mother tongue ( $p$-value $=.001)$ or using technological tools ( $p$-value $=.000)$.

\subsubsection{Assessment of the competences needed to practise medical translation}

Translators assessed the importance of a list of competences for translating medical texts. The Likert scale used was the following: not essential (1), somewhat important (2), relatively important (3), very important (4), essential (5).

To facilitate the analysis of the results, competences were grouped into seven different blocks according to their nature (see Appendix 1), as follows:

(1) Linguistic, textual and terminological issues

(2) Thematic issues

(3) Cultural issues

(4) Documentary and instrumental issues

(5) Socio-professional and interpersonal issues

(6) Attitudinal and psycho-physiological issues

(7) Strategic issues

Table 1 shows the list of competences assessed. ${ }^{5}$

[Table 1 near here]

As it can be seen, the average score for all the competences was higher than 3.4, which means that none of them were considered not essential or only somewhat important.

The most highly-rated competences were related to linguistic issues (block 1), i.e. mastering working languages, especially the mother tongue.

Translators also attached special importance to attitudinal and psychophysiological competences (block 6), since seven of the nine included in the list were rated above 4 . The most highly-rated competences were common sense, which was highlighted by all the participants in the qualitative exploratory study (see Muñoz-Miquel 2014, 177), and critical attitude.

The top ten competences also included the ability to evaluate the quality and reliability of documentary resources, and the ability to use specialised terminology accurately according to the context and to mimic the phraseology employed by specialists. This is in consonance with the results presented in Section 3.1.2.3 on the 
difficulties the translators face, since finding reliable reference material and choosing the most appropriate terminological equivalent were rated among the most difficult aspects of medical translation.

The ability to adapt to the requirements of the translation assignment, to accept modifications from clients or reviewers, and to review or proofread and provide appropriate justifications for suggested changes were also very highly-rated competences. These results are also consistent with the fact that most translators spend part of their work time reviewing or proofreading.

Regarding thematic competences (block 2), translators reported that it was especially important to be able to acquire thematic knowledge $a d$ hoc i.e. to research new topics for a specific translation. The importance of this thematic competence could be related to wide variety of topics that medical translators are required to deal with (see Section 3.1.2.2).

Other important competences included: command of the characteristics and conventions of medical genres, knowledge of the main documentary sources, and knowledge of the characteristics of medical terminology.

Table 1 also shows that the competence with the lowest rating was of a cultural nature (i.e. knowledge of differences in healthcare systems, in conceptions of health and disease, etc.). Although this result is consistent with what some authors (Rouleau 1994; Fischbach 1998; Montalt and González 2007) have stated about the characteristics of medical translation (dealing with cultural issues is not usually a characteristic trait of this specialisation), in the context of this survey it is noteworthy because respondents highlighted translating cultural asymmetries as one of the main difficulties encountered (see Section 3.1.2.3). The low priority given to the cultural competence could be explained by the type of genres that the translators are usually required to translate (see Section 3.1.2.2), where they rarely need to resolve with cultural asymmetries. Therefore, it seems that translators do not very often have to face cultural asymmetries, but when they do have to translate them, they find them difficult.

Table 1 also shows that no priority was given to having knowledge of the characteristics of the medical translation market or managing projects. It is also noteworthy that the ability to use CAT or other ICT tools featured among the least highlyrated competences, despite being the second reason why translators needed to undertake additional self-directed training (see Section 3.1.2.4). 


\subsubsection{Opinions about postgraduate medical translation courses}

We firstly asked translators to rate, from 1 to 5 , a list of content that they felt should be included in a postgraduate medical translation course. For our respondents, the most important aspect was undertaking real translation assignments (4.56). This was followed by medical terminology notions (4.47); search techniques, terminology management and reliability of documentary sources (4.34); background medical knowledge (4.32); and revision of students' translation assignments by medical experts (4.32). We can see that these results are consistent with those obtained in the assessment of competences.

Secondly, we asked translators their opinions on whether postgraduate courses should take the students' different academic backgrounds into account. The majority (58\%) considered that the courses should be primarily the same for TLBs and TSBs, but with some different course units according to students' academic profile; $25 \%$ stated that courses should be entirely different for TLBs and TSBs; and 17\% considered that they should be exactly the same. The list of possible answers also included an additional option, i.e. 'Receiving specific training in medical translation is not necessary', which was not selected by any respondent.

\subsection{Empirical study 2: Academic perspective}

Having explained the results of the socio-professional study, we now turn to the competences that students are expected to acquire, according to the analysis of syllabuses, in postgraduate courses in which medical translation is taught, either exclusively (two courses in Spain) or together with other areas of specialisation (six in all).

The postgraduate courses analysed are shown in Table 2. Their most notable characteristics were as follows: the specialised courses are addressed both to students with a linguistic background and to those with a scientific background (although no different course units are offered depending on their academic profile), and the nonspecialised courses are generally offered to students with the required linguistic level; they all focus on the English-Spanish language combination (although nine courses offer a wider variety of language pairs); they are all worth 60 ECTS credits, except the programme offered at Córdoba University, which is worth 20 ECTS credits.

[Table 2 near here] 
Table 3 displays a list of the competences sorted according to the total number of postgraduate courses that mention them. It should be noted that two competences not included in the list given to the professional translators surveyed had to be added. These competences (see the grey cells in Table 3) are more closely related to the academic than to the professional environment, and therefore they appeared in the course syllabuses analysed.

[Table 3 near here]

The 'Total' column shows that two competences are mentioned in all eight courses: knowledge of the characteristics and conventions of medical genres; and ability to determine the requirements of the assignment and to work accordingly. This shows how important these competences are in the academic context.

As regards the genre-related competence, five postgraduate course syllabuses included some examples of the genres covered in class. Among those most frequently mentioned were research articles, fact sheets for patients, medical reports, medical manuals and popular science articles.

Table 3 also shows that three of the five competences referred to in seven postgraduate courses are related to documentary and instrumental issues (block 4). Having a good command of CAT/ICT tools, knowing the main documentary sources, and being able to evaluate their quality and reliability are priorities for the programmes studied. It is also important to have a good command of the mother tongue and a basic grasp of the characteristics of medical translation.

Most postgraduate courses (between five and six) also provide their students with the necessary knowledge and skills to be familiar with the characteristics of medical terminology, to use the appropriate terms in context, to revise and proofread their own and others' translations, to adapt to the requirements of the translation assignment, and to work under conditions that simulate professional practice.

The significant number of competences that none of (or at most one or two) postgraduate courses refer to is noteworthy. The vast majority are attitudinal and psychophysiological (block 6), such as common sense, constant self-improvement, and awareness of one's own strengths and limitations. Having an excellent command of one's working languages and being able to discuss doubts with colleagues and experts in the 
field are also among the least mentioned competences. Cultural competence is also among those that are not referred to.

A more detailed analysis of the results, not included in the present paper due to space constraints, also revealed some differences between the postgraduate courses that specialise on medical translation and those that are non-specialised. Specialised courses differ from non-specialised ones because their syllabuses refer to a wider range of competences. This may be because more course units were analysed in the specialised programmes. These additional competences are of a socio-professional, documentary and especially thematic nature, such as basic medical knowledge and the ability to acquire thematic knowledge ad hoc, ${ }^{6}$ knowledge of the characteristics of the professional market, ability to manage professional practice, knowledge of advanced search techniques, and ability to create and manage one's own documentary resources.

\section{Comparing the two perspectives}

Having provided separate analysis of the results of the socio-professional and academic investigations, this section compares both sets of results. In this comparative analysis, competences are taken as the main assessment instruments to determine the convergences and divergences between the profession and academia. To facilitate the comparison of the results, the convergences and divergences are discussed in terms of the blocks of competences (see section 3.1.3. for the list of blocks). In addition, some tasks and instruments (Galán-Mañas and Hurtado 2015) are suggested for fostering the acquisition and assessment of competences in areas where academia and professional practice tend to diverge, in an attempt to help bridge this gap.

Regarding block 1 (i.e. linguistic, textual and terminological issues), the results show that there are a number of similarities between the competences derived from analysis of the translators' responses to the survey and those identified from the analysis of syllabuses. The first similarity relates to knowledge of the characteristics of different medical genres, since this is regarded as a key competence by both professionals and universities. However, there is not a perfect match between the genres most often translated in the market and those that students cover in the course units they study at university. Although some syllabuses include two of the genres that are most frequently translated in professional practice, i.e. fact sheets for patients and research articles, there are others that are overlooked in medical translation courses, e.g. clinical trial protocols, 
informed consents and instruction manuals for medical devices. ${ }^{7}$ As texts to be translated are the most widely used instrument for students to acquire competences and for trainers to assess them (Galán-Mañas and Hurtado 2015, 70), it is important to pay special attention to genre selection (Saldanha and O'Brien 2014, 97) when designing training. If we take into account the results obtained in these studies, the selection could be based partly on the requirements of the professional market. Thus, postgraduate courses could start with the less specialised genres, such as fact sheets for patients or informed consents, and then move on to more specialised and complex genres, such as research papers or clinical trial protocols.

Another important similarity relates to terminological issues. Knowledge of the characteristics of medical terminology and the ability to use specialised terminology accurately are very important competences for translators and are referred to in postgraduate courses, particularly in the specialised ones. It is not clear whether some of the terminological problems that professionals face, as described in the results presented in Section 3.1.2.3 (e.g. interpreting abbreviations and acronyms), are dealt with in university courses, as detailed information of this kind is not usually provided in the syllabuses. In order to ensure that these competences are acquired, it would be advisable to supplement translations themselves (which are the main assessment instrument used in all the courses analysed) with other pre-translation tasks such as explaining different types of abbreviations, using etymology to define terms, finding synonyms for given terms, etc. (Montalt and González 2007; Montalt 2012; Galán-Mañas and Hurtado 2015).

The competence most highly-rated by our sample of translators, i.e. mastering working languages, is referred to in only one postgraduate course. This can be considered a 'necessary' divergence because, as is also highlighted by authors such as Huertas Barros and Vine (2017), mastering working languages is generally a requirement for students who wish to enrol on a postgraduate translation course. It seems logical, therefore, that language acquisition is not specifically referred to. What postgraduate courses do emphasise is having excellent writing skills in one's mother tongue, and this is consistent with translators' opinions.

We also find similarities in block 2 (thematic issues). In the specialised courses students are taught not only basic medical knowledge but also how to acquire medical knowledge ad hoc to be able to translate texts on a wide variety of medical topics. Professional translators also value these competences, which are especially important for TLBs, as their main difficulty is understanding specialised concepts and their main 
training need is to acquire thematic knowledge. Such thematic knowledge can, in turn, help improve their understanding of original texts, especially if these are not particularly well written, which is sometimes the case in the medical field (see Section 3.1.2.3). What remains unknown, since the information is not usually provided in the syllabuses, is whether topics chosen for the students to translate provide opportunities to develop thematic knowledge competences and their ability to acquire ad hoc knowledge. It is also not clear if the topics coincide with those most commonly needed in the market, e.g. those related to the pharmaceutical industry, medical instruments or oncology. In any event, as in the case of genres, the topics dealt with in the texts to be translated by students could also be chosen to fit market trends. On the other hand, tests and questionnaires could be especially useful in specialised postgraduate courses to check that basic medical knowledge has been assimilated (Martínez and Hurtado 2001, 282).

In block 3 (cultural issues), the divergences between the two perspectives are striking. Although the cultural competence is among those least highly-rated by translators, we have seen that cultural problems play a significant role in the medical field. The fact that respondents cited translating cultural asymmetries as the most difficult problem they have to deal with shows that medical translation has a greater cultural element to it than has traditionally been believed. However, the syllabuses of postgraduate courses do not include this competence. This result could indicate that in the academic context the cultural competence may be traditionally linked not to medical translation in the written mode (especially when compared to audiovisual or literary translation), but to oral medical interpreting, especially in public services (Crezee, Mikkelson and MonzonStorey 2015), an area of specialisation which was not analysed in this study. This could also partially explain why translators do not seem to be adequately prepared to deal with cultural asymmetries. This important divergence could be overcome by including, among others, tasks in which students have to identify culturally-related terms and references that differ between the source and target cultures (e.g. beliefs about health and disease, qualifications or roles of healthcare personnel, names of drugs) and consider ways of solving them, such as finding 'descriptive equivalents' (Newmark 1998, 83), providing explanations, etc. Students could also be provided with source texts where cultural asymmetries are more likely to be found, such as quality-of-life questionnaires (Congost 2010), which are in turn among the most frequently translated genres in the professional context. 
In block 4 (documentary and instrumental issues), we find both convergences and divergences. Two of the most important competences for translators (i.e. knowledge of the main documentary sources and ability to evaluate their quality and reliability) are cited in seven of the eight postgraduate courses analysed. Therefore, we can state that the profession and academia are quite closely aligned in this regard.

The main divergence is related to having a good command of CAT/ICT tools. Although the syllabuses of seven courses refer to acquiring this competence, it is among the least highly-rated by translators. A possible explanation for this might be that respondents do not give priority to this competence because CAT tools are constantly evolving, and their use generally depends on client preference. This could explain why a considerable number of translators taught themselves how to use these tools. Given this situation, university courses could give less priority to CAT/ICT tools (which could be taught in specific translation technology courses) in favour of other competences that seem to be more necessary for medical translation (such as thematic or terminological competences). This would be especially important in the non-specialised courses, where the number of class hours devoted to medical translation is much lower than in the specialised courses.

As regards block 5 (socio-professional and interpersonal issues), a considerable degree of convergence is observed between the responses and profiles of the professionals, on the one hand, and university courses, especially the specialised ones, on the other. We can see that in both contexts similar importance is attached to certain competences, such as adapting to the requirements of the assignment, which is one of the most important in this block, and advertising professional services or managing projects, which are among those considered least important.

A divergence is found, however, in relation to knowledge of the characteristics of the medical translation market. While the syllabuses of five postgraduate courses mention this competence, translators do not prioritise this competence, rating it the least important competence. This could be another 'necessary' divergence between the profession and academia: knowledge of the medical translation market could be especially relevant for those wishing to specialise in and gain access to the market, i.e. students, but for those who already know and work within it, i.e. professional translators, this is not such a priority.

The competences in block 6 (attitudinal and psycho-physiological issues) are where we find most discrepancies between the two perspectives studied. While translators 
prioritise most of these competences (especially common sense, constant search for quality, critical attitude, and awareness of one's own strengths and limitations), postgraduate courses hardly mention them. This could be due to the fact that attitudinal and psycho-physiological issues are generally more difficult to assess and measure in class, which could explain why these competences do not usually appear in syllabuses. Although further studies with trainers are needed to find out whether these competences are worked on in class, instruments such as translation diaries (to record problems encountered, errors, documentation sources, evaluation of results, etc.) (Martínez and Hurtado 2001, 284) and discussions in class about critical issues in medical translation could help foster the acquisition and assessment of such competences.

In block 7 (i.e. strategic competences) we find more convergences, since the significant number of courses that mention the ability to determine the characteristics of the assignment and to revise/proofread and justify changes (eight and six courses respectively) is consistent with the high value that professional translators attribute to these competences. The importance of revising and proofreading as a professional activity is further evidence of their relevance.

It is also interesting to note that the ability to work under conditions that simulate professional practice, a competence included only in the list used to analyse the academic perspective, is worked on in five out of the eight courses. Although this result is generally in line with the opinions of translators, since they regard undertaking real translation assignments as the most important element that should be included in a course, this competence is so crucial that we consider it should be addressed and assessed in all university courses. One way to strengthen this, as Galán-Mañas and Hurtado suggest $(2015,76)$, would be to provide students with translation commissions that he been received from real clients, following specific requirements if provided (e.g. a given style guide), with a specific deadline, a quote and an invoice.

Apart from convergences and divergences in the competences already mentioned, comparing the two perspectives also highlights some other issues that are worth mentioning. On the one hand, we find some differences between the tasks that students and professionals perform. Postgraduate courses seem to focus on 'traditional' translation and revision tasks. Translators, however, perform a wider range of activities that relate to new requirements and forms of communication. Turning research papers into summaries for patients or presentations for conferences is just one example of how the work of medical translators is not restricted to translating between different languages. 
Intralingual translations (Zethsen 2009) or genre shifts (Montalt and González 2007) also form part of a medical translator's multifaceted activity, yet no trace of them is found in university course syllabuses. Postgraduate courses could address these new professional requirements by including tasks that enable students to acquire intralingual translation skills (Muñoz-Miquel et al. forthcoming) These tasks could range from pre-translation ones, such as determinologising ${ }^{8}$ specialised terms and concepts using various strategies; summarising texts and comparing the characteristics of 'intergenerically derived' genres (Askehave and Kastberg 2001, 491), e.g. patient information leaflets and summaries of product characteristics; to undertaking real intralingual translation assignments (MuñozMiquel et al. 2017; Muñoz-Miquel et al. forthcoming).

On the other hand, the results of the socio-professional study also indicate, as expected, that medical translators have varied academic backgrounds. This is possibly the reason why postgraduate courses, especially the specialised ones, are open to students with both linguistic and scientific backgrounds, but without making distinctions according to their profile. This is not consistent with the reality of professional practice or with translators' opinions, which reveal substantial differences between TLBs and TSBs that could affect their training. The issues that the two groups find most difficult and the training needs they identify suggest that students with a linguistic background need to strengthen their conceptual and terminological competences, whereas those with a scientific background need to strength their ability to express themselves in their mother tongue or to acquire cultural knowledge. In addition, the majority of the translators surveyed thought that postgraduate courses should include a range of course units adapted to students' academic profiles so as to meet each group's specific needs. Yet in spite of this, as we have shown, none of the courses analysed in this paper addressed this question of different training needs. Consideration should therefore be given to the possibility of including different course units or training blocks according to students' academic backgrounds. Another possibility would be to hold workshops or seminars designed to complement the official curriculum, which would be a way to offset any shortcomings in the competences of different student profiles. 


\section{Conclusions and future areas of research}

This paper has presented the results of two empirical studies that were used to assess the suitability of postgraduate programmes in medical translation as preparation for the reality of professional practice, taking the notion of competence as a criterion.

Comparing the competences derived from what medical translators think of and do in their professional practice with those competences identified from the analysis of course syllabuses leads to the conclusion that postgraduate courses, especially those specialising in medical translation, are generally in line with the requirements of the practice of medical translation in the English-Spanish language pair. This is especially evident for thematic, terminological, documentary and textual competences, such as the following: knowledge of the characteristics and conventions of different medical genres, ability to use specialised terminology, ability to acquire basic medical knowledge and to acquire it ad hoc, knowledge of the main sources of documentary information, and ability to evaluate their quality and reliability. These competences also coincide with those referred to in the literature on medical translation.

However, the assessment of competences has also revealed some divergences between the profession and academia, and these raise a number of questions that could be taken into account when designing, planning and improving existing and new postgraduate courses. Firstly, more emphasis could be placed on developing attitudinal competences (e.g. by means of translation diaries, reasoned translations, discussions about critical issues) as well as cultural competences (e.g. through translations of genres that are more culturally marked) that would help future medical translators to deal with cultural asymmetries in the written as well as the oral mode. Secondly, the choice of genres and topics to be translated by students could be based partly on those most commonly found in the professional market. Thirdly, it would be interesting to consider performing activities other than 'traditional' translations, such as intralingual translations. These activities (which could range from specific pre-translation tasks to intralingual translation assignments) could, in turn, foster the ability to adapt to different tasks and situations, and promote the idea of a versatile medical translator capable of going beyond what is traditionally known as 'translation proper' (Zethsen 2007, 281). Finally, courses could also take into account the fact that students with different academic profiles generally have different training needs, which may have a direct impact on curriculum design. 
Empirical studies of this kind can help bridge the gap between professional practice and training. The methodology used in this case study could be applied to other translation specialisms in which the degree to which training programmes fit the profession needs to be assessed. We should bear in mind, however, that both the translation market and the professional context are prone to change, and that the trends indicated in this study cannot be the only reference factor when assessing the suitability of postgraduate courses as preparation for professional practice. Other didactic and contextual criteria, which might affect curricular planning, e.g. institutional constraints, trainee profiles, disciplinary considerations, among others, also need to be considered (Kelly 2005, 22). Therefore, a reasonable balance has to be struck between what happens in the professional context and the pedagogic principles that can lead to certain competences being acquired and assessed in the classroom.

As for the limitations of this study, several issues need to be taken into account. Firstly, although the socio-professional study collected a considerable number of responses, the results obtained are not representative of the medical-translator population as a whole, but only of the sample itself, because of the limitations of the non-probabilistic sampling method used. Secondly, although course syllabuses are public documents in which the planning of course units must be reflected as faithfully as possible, there may be divergences between what is stated and what actually happens in class, as a result of modifications that trainers may introduce. Therefore, the results of this analysis cannot be considered a true reflection of reality, although they may come close to it. Another limitation of this study arises from the disparate nature of the syllabuses studied (some were more detailed than others), with the result that not all the postgraduate courses were analysed under the same conditions. Finally, we should also take into account that this study is related to a single language pair (English-Spanish) and that the situation regarding medical translation teaching and professional practice in other language combinations might be different.

As for future research, these results could be complemented by conducting interviews with curriculum planners and trainers to gain a more complete and accurate view of the competences that students are expected to acquire and of the reasons for doing so. Another possible line of research is to conduct surveys with translators' employers and clients to determine their views about the competences they seek when hiring medical translation services. These studies will provide further in-depth information to help universities assess how far training programmes develop the competences identified in 
the job market, with the ultimate purpose of helping to bridge the gap between pedagogy and the profession.

\section{References}

Askehave, I., and P. Kastberg. 2001. "Intergeneric Derivation: On the Genealogy of an LSP Text." Text \& Talk 21 (4): 489-513.

Balliu, C. 2001. "Les traducteurs: ces médecins légistes du texte." Meta: Translators' Journal 46 (1): 92-102. doi: 10.7202/001961ar.

Calvo Encinas, E. 2010. "Análisis curricular de los estudios de Traducción e Interpretación en España. Perspectiva del estudiantado.” PhD. diss., Universidad de Granada.

Calvo Encinas, E. 2011. "Translation and/or Translator Skills as Organising Principles for Curriculum Development Practice." JoSTrans: Journal of Specialised Translation 16: 5-25.

Cerezo Merchán, B. 2012. "La didáctica de la traducción audiovisual en España: un estudio de caso empírico-descriptivo.” PhD. diss., Universitat Jaume I.

Congost Maestre, N. 2010. "El lenguaje de las Ciencias de la Salud. Los cuestionarios de salud y calidad de vida y su traducción de inglés al español." PhD. diss., Universidad de Alicante.

Crezee, Ineke, H. M., H. Mikkelson, and L. Monzon-Storey. 2015. Introduction to Healthcare for Spanish-speaking Interpreters and Translators. Amsterdam: John Benjamins.

Félix Fernández, L., and E. Ortega Arjonilla, eds. 1998. Traducción e interpretación en el ámbito biosanitario. Granada: Comares.

Fischbach, H., ed. 1998. Translation and Medicine. Amsterdam: John Benjamins.

Fortea Bagán, M. 2007. Planificación y diseño de la docencia universitaria con créditos ECTS y algunas consideraciones sobre el diseño de los nuevos planes de estudio. Borrador v.1, septiembre de 2007. Castelló de la Plana: Universitat Jaume I.

Galán-Mañas, A., and A. Hurtado Albir. 2015. "Competence Assessment Procedures in Translator Training." The Interpreter and Translator Trainer 9 (1): 63-82. doi: 10.1080/1750399X.2015.1010358.

González, J., and R. Wagenaar. 2003. Tuning Educational Structures in Europe. Final Report. Phase One. Bilbao: Universidad de Deusto. 
Huertas Barros, E., and J. Vine. 2015. "Special Issue of The Interpreter and Translator Trainer Volume 12, Number 1. New Perspectives in Assessment in Translator Training" The Interpreter and Translator Trainer 9 (3): 370-371. doi: 10.1080/1750399X.2015.1103093.

Huertas Barros, E. and J. Vine. 2017. "Current Trends on MA Translation Courses in the

UK: Changing Assessment Practices on Core Translation Modules." The Interpreter and Translator Trainer 12 (1). doi: 10.1080/1750399X.2017.1400365.

Hurtado Albir, A. 2007. "Competence-based Curriculum Design for Training Translators." The Interpreter and Translator Trainer 1 (2): 163-195. doi: 10.1080/1750399X.2007.10798757.

Jensen, M. N., and K. K. Zethsen. 2012. "Translation of Patient Information Leaflets Trained Translators and Pharmacists-cum-translators: A comparison." Linguistica Antverpiensia 11: 31-49.

Kelly, D. 2002. "Un modelo de competencia traductora: bases para el diseño curricular." Puentes 1: 9-20.

Kelly, D. 2005. A Handbook for Translator Trainers. A Guide to Reflective Practice. Manchester: St. Jerome.

Lázaro Gutiérrez, R. 2014. "Perspectivas en la formación de posgrado en traducción biosanitaria." Skopos 4: 167-185.

Lee-Jahnke, H. 2005. “Teaching Medical Translation: An Easy Job?”Panace@, Revista de Medicina, Lenguaje y Traducción 6 (20): 81-84.

Li, D. 2012. Curriculum Design, Needs Assessment and Translation Pedagogy with Special Reference to Translation Training in Hong Kong. Saarbrücken: Lap Lambert.

Martínez Melis, N., and A. Hurtado Albir. 2001. "Assessment in Translation Studies: Research Needs.” Meta: Translators' Journal 46 (2): 272-287.

Martínez Villermosa, L. 2016. "La enseñanza por competencias en la traducción especializada: el caso de la traducción médica." Paper presented at the Congreso Internacional de Traducción Especializada EnTRetextos, Valencia, April 27-29.

Mayor Serrano, M. B. 2006. "Hacia la especialización en los estudios de Traducción." Panace@, Revista de Medicina, Lenguaje y Traducción 7 (23): 81-87.

Montalt Resurrecció, V. 2012. “A Case for Content-based Approach to Translators' Education." Paper presented at the First International Conference on Research into Didactics of Translation, Barcelona, June 21-22. 
Montalt Resurrecció, V., and M. González Davies. 2007. Medical Translation Step by Step: Learning by Drafting. Manchester: St. Jerome.

Muñoz-Miquel, A. 2014. "El perfil y las competencias del traductor médico desde el punto de vista de los profesionales: una aproximación cualitativa.", Trans: Revista de Traductología 18: 163-181.

Muñoz-Miquel, A. 2016a. "Bridging the gap between professional practice and university training through socio-professional research: The case of medical translation." In From the Lab to the Classroom and Back Again: Perspectives on Translation and Interpreting Training, edited by C. Martín de León, and V. González-Ruiz, 257294. Frankfurt am Main: Peter Lang.

Muñoz-Miquel, A. 2016b. "La enseñanza de la traducción médica en los programas de posgrado españoles: ¿qué competencias se enseña a los estudiantes?” Sendebar 27: 123-150.

Muñoz-Miquel, A. Forthcoming. "Differences between linguists and subject-matter experts in the medical translation practice: An empirical descriptive study with professional translators." Target: International Journal of Translation Studies.

Muñoz-Miquel, A., P. Ezpeleta-Piorno, and P. Saiz-Hontangas. Forthcoming. "Intralingual translation in healthcare settings: Strategies and proposals for medical translator training." MonTI: Monografías de Traducción e Interpretación 10.

Muñoz-Miquel, A., and P. Saiz-Hontangas. 2017. "Intralingual translation in healthcare settings: Description of a case study and implications for medical translator training." Paper presented at the Current Challenges of Medical Translation. Translating Europe Workshop, Gdańsk, May 18.

Navascués Benlloch, I., and A. Hernando Saudan. 1998. "El médico traductor de textos médicos." In Traducción e interpretación en el ámbito biosanitario, edited by L. Félix Fernández, and E. Ortega Arjonilla, 147-158. Granada: Comares.

Newmark, P. 1998. A Textbook of Translation. Hemel Hempstead: Prentice Hall International.

O’Neill, M. 1998. "Who Makes a Better Medical Translation: The Medically Knowledgeable Linguist or the Linguistically Knowledgeable Medical Professional? A Physician's Perspective." In Translation and Medicine, edited by H. Fischbach, 69-80. Amsterdam: John Benjamins.

PACTE. 2003. "Building a Translation Competence Model." In Triangulating Translation: Perspectives in Process Oriented Research, edited by F. Alves, 43-66. 
Amsterdam: John Benjamins.

Rouleau, M. 1994. La traduction médicale. Une approche méthodique. Montreal: Linguatech.

Sachinis, M. 2011. "Curriculum Renewal in Greek Taught Postgraduate Translation Courses: Aligning Student Needs and Translation Market Requirements.” PhD. diss., Imperial College London.

Saldanha, G., and S. O'Brien. 2014. Research Methodologies in Translation Studies. New York: Routledge.

Toudic, D., coord. 2012. Optimising Professional Translator Training in a Multilingual Europe. Progress Report. Brussels: European Comission.

Vigier Moreno, F. J. 2010. "El nombramiento de traductores-intérpretes jurados de inglés mediante acreditación académica: descripción de la formación específica y del grado de satisfacción de los egresados.” PhD. diss., Universidad de Granada.

Wakabayashi, J. 1996. “Teaching Medical Translation.” Meta: Translators' Journal 41 (3): $356-365$.

Yániz Álvarez de Eulate, C., and L. Villardón Gallego. 2006. Planificar desde competencias para promover el aprendizaje. Bilbao: Mensajero.

Zethsen, K. K. 2007. "Beyond Translation Proper. Extending the Field of Translation Studies.” TTR: Traduction, Terminologie, Redaction 20 (1): 281-308.

Zethsen, K. K. 2009. “Intralingual Translation: an Attempt at Description." Meta: Translators' Journal 54 (4): 795-812. 


\section{Appendix 1: List of competences}

\section{B1. Linguistic, textual and terminological issues}

Command of working languages.

Ability to carry out reflective and analytical readings.

Excellent writing skills in the mother tongue.

Knowledge of the characteristics and conventions of the main medical genres in the working languages.

Knowledge of the characteristics of medical terminology and phraseology (Greek and Latin prefixes and suffixes, abbreviations, etc.).

Ability to use specialised terminology accurately according to the context and to mimic the phraseology employed by the target group of specialists to whom the translation is addressed.

Knowledge of the characteristics of medical translation (main difficulties, theoretical reflections on the field, etc.)

\section{B2. Thematic issues}

Basic medical knowledge (anatomy, physiology, etc.).

Ability to acquire thematic knowledge ad hoc to solve problems related to the medical topics to be translated.

\section{B3. Cultural issues}

Knowledge of the differences in healthcare systems, beliefs about health and disease, qualifications or positions of healthcare personnel, etc., in working cultures.

\section{B4. Documentary and instrumental issues}

Knowledge of the main medical documentation sources (dictionaries, glossaries, etc.).

Ability to evaluate the quality and reliability of documentary resources.

Knowledge of advanced search techniques (Boolean operators, database searches, etc.).

Ability to create and manage one's own documentary resources (glossaries, translation memories, etc.).

Ability to discuss doubts with colleagues and experts in the field.

Mastering the use of CAT or other ICT tools.

\section{B5. Socio-professional and interpersonal issues}

Knowledge of the characteristics of the medical translation market (sectors, clients, most commonly requested professional profiles, etc.). 
Ability to manage one's own professional practice (giving estimates, invoicing, etc.).

Ability to keep up to date with the latest trends in the sector.

Ability to deal professionally with clients, colleagues, experts in the field, etc.

Ability to manage projects.

Ability to work in teams and in collaboration with other colleagues/experts.

Ability to advertise professional services and to search for customers.

Ability to adapt to the requirements of the translation assignment (client's specifications, deadlines, etc.).

Ability to accept suggestions, constructive criticism and modifications from clients and reviewers.

Knowledge of and respect for professional codes of ethics and conduct.

\section{B6. Attitudinal and psycho-physiological issues}

Ability to systematise the most usual tasks.

Interest in the field to be translated.

Sensitivity to language and culture.

Constant self-improvement and enhancement ability.

Constant search for quality.

Awareness of one's own strengths and limitations, and of professional identity.

Ability to adapt to new tasks and situations.

Common sense.

Critical attitude.

\section{B7. Strategic issues}

Ability to determine the requirements of the assignment and to work accordingly.

Ability to review or proofread one's own and others' translations and works, and to provide appropriate justifications.

Ability to work under real conditions that simulate professional practice. 
Table 1. Assessment of a given list of competences.

\begin{tabular}{|c|c|c|}
\hline Competences (abbreviated) & $\begin{array}{l}\text { Competences } \\
\text { block }\end{array}$ & Mean score \\
\hline Command of working languages. & 1 & 4.86 \\
\hline Writing skills in mother tongue. & 1 & 4.80 \\
\hline Common sense. & 6 & 4.68 \\
\hline Constant search for quality. & 6 & 4.63 \\
\hline Critical attitude. & 6 & 4.62 \\
\hline Evaluate quality/reliability of documentary resources. & 4 & 4.53 \\
\hline Use specific terminology and mimic phraseology. & 1 & 4.49 \\
\hline Adapt to assignment's requirements. & 5 & 4.46 \\
\hline Reflective and analytical readings. & 1 & 4.46 \\
\hline Accept suggestions/modifications. & 5 & 4.43 \\
\hline Review/proofread and justify. & 7 & 4.37 \\
\hline Acquire thematic knowledge ad hoc. & 2 & 4.36 \\
\hline Self-awareness of strengths/limitations. & 6 & 4.33 \\
\hline Knowledge of documentation sources. & 4 & 4.33 \\
\hline Sensitivity to language/culture. & 6 & 4.30 \\
\hline Knowledge of characteristics of medical genres. & 1 & 4.30 \\
\hline Constant self-improvement. & 6 & 4.29 \\
\hline Knowledge of professional codes of ethics. & 5 & 4.26 \\
\hline Knowledge of characteris tics of medical terminology. & 1 & 4.22 \\
\hline Adapt to new tasks/situations. & 6 & 4.20 \\
\hline Determine assignment's requirements and work accordingly. & 7 & 4.14 \\
\hline Deal with clients/colleagues/experts in the field. & 5 & 4.04 \\
\hline Interest in the field to be trans lated. & 6 & 4.00 \\
\hline Knowledge of advanced search techniques. & 4 & 3.98 \\
\hline Basic medical knowledge. & 2 & 3.95 \\
\hline Systematise the most usual tasks. & 6 & 3.89 \\
\hline Ask doubts to colleagues/experts. & 4 & 3.89 \\
\hline Create/manage one's own documentary resources. & 4 & 3.87 \\
\hline Keep up to date. & 5 & 3.83 \\
\hline Manage own's professional practice. & 5 & 3.83 \\
\hline Mastering CAT or other ICT tools. & 4 & 3.75 \\
\hline Work in teams/in collaboration. & 5 & 3.63 \\
\hline Advertise professional services and search for clients. & 5 & 3.60 \\
\hline Manage projects. & 5 & 3.57 \\
\hline Knowledge of characteristics of medical translation market. & 5 & 3.55 \\
\hline $\begin{array}{l}\text { Knowledge of differences in healthcare systems, beliefs about } \\
\text { health/sickness, etc. }\end{array}$ & 3 & 3.47 \\
\hline
\end{tabular}


Table 2. Postgraduate courses analysed.

\begin{tabular}{|l|l|}
\hline \multicolumn{2}{|c|}{ Posgraduate programmes that are specific to medical translation } \\
\hline Master's Degree in Medical and Healthcare Translation & Jaume I University \\
\hline Master's Degree in Biomedical and Pharmaceutical Translation & Pompeu Fabra University \\
\hline \multicolumn{2}{|c|}{ Posgraduate programmes that are non-specific to medical translation } \\
\hline $\begin{array}{l}\text { Master's Degree in Intercultural Communication, Public Service Interpreting and } \\
\text { Translation }\end{array}$ & Alcalá University \\
\hline $\begin{array}{l}\text { University Expert Certificate in Translation in Specialised Contexts: Health Sciences } \\
\text { and Agrofood Industry }\end{array}$ & Córdoba University \\
\hline Master's Degree in Publishing Translation & Murcia University \\
\hline Master's Degree in Translation Applied to the World of Publishing & Málaga University \\
\hline Master's Degree in International Communication, Translation and Interpreting & Pablo de Olavide University \\
\hline Master's Degree in Translation for International Communication & Vigo University \\
\hline
\end{tabular}


Table 3. Competences mentioned in the course syllabuses analysed.

\begin{tabular}{|c|c|c|c|c|}
\hline \multirow[b]{2}{*}{ Competences (abbreviated) } & \multirow{2}{*}{$\begin{array}{c}\text { Competences } \\
\text { block }\end{array}$} & \multicolumn{3}{|c|}{ No. of postgraduate courses } \\
\hline & & $\begin{array}{c}\text { Specific } \\
\text { (2) }\end{array}$ & \begin{tabular}{|c|} 
Non- \\
specific (6)
\end{tabular} & Total \\
\hline Knowledge of characteristics of medical genres. & 1 & 2 & 6 & 8 \\
\hline Determine assignment's requirements and work accordingly. & 7 & 2 & 6 & 8 \\
\hline Writing skills in mother tongue. & 1 & 2 & 5 & 7 \\
\hline Knowledge of characteristics of medical translation. & 1 & 2 & 5 & 7 \\
\hline Mastering CAT or other ICT tools. & 4 & 2 & 5 & 7 \\
\hline Knowledge of documentation sources. & 4 & 2 & 5 & 7 \\
\hline Evaluate quality/reliability of documentary resources. & 4 & 2 & 5 & 7 \\
\hline Knowledge of characteristics of medical terminology. & 1 & 2 & 4 & 6 \\
\hline Review/proofread and justify. & 7 & 2 & 4 & 6 \\
\hline Reflective and analytical readings. & 1 & 1 & 4 & 5 \\
\hline Use specific terminology and mimic phraseology. & 1 & 2 & 3 & 5 \\
\hline Knowledge of advanced search techniques. & 4 & 2 & 3 & 5 \\
\hline Create/manage one's own documentary resources. & 4 & 2 & 3 & 5 \\
\hline Knowledge of characteristics of medical translation market. & 5 & 2 & 3 & 5 \\
\hline Work in teams/in collaboration. & 5 & 2 & 3 & 5 \\
\hline Adapt to assignment's requirements. & 5 & 2 & 3 & 5 \\
\hline $\begin{array}{l}\text { Ability to work under conditions that simulate the professional } \\
\text { practice. }\end{array}$ & 7 & 2 & 3 & 5 \\
\hline Acquire thematic knowledge ad hoc. & 2 & 2 & 2 & 4 \\
\hline Manage own's professional practice. & 5 & 2 & 2 & 4 \\
\hline Deal with clients/colleagues/experts in the field. & 5 & 1 & 3 & 4 \\
\hline Constant search for quality. & 6 & 2 & 2 & 4 \\
\hline Knowledge of professional codes of ethics. & 5 & 1 & 2 & 3 \\
\hline Critical attitude. & 6 & 1 & 2 & 3 \\
\hline Basic medical knowledge. & 2 & 2 & 0 & 2 \\
\hline Accept suggestions/modifications. & 5 & 1 & 1 & 2 \\
\hline Systematise the most usual tasks. & 6 & 1 & 1 & 2 \\
\hline Adapt to new tasks/situations. & 6 & 0 & 2 & 2 \\
\hline Command of working languages. & 1 & 0 & 1 & 1 \\
\hline Ask doubts to colleagues/experts. & 4 & 1 & 0 & 1 \\
\hline Keep up to date. & 5 & 1 & 0 & 1 \\
\hline Advertise professional services and search for clients. & 5 & 1 & 0 & 1 \\
\hline Sensitivity to language/culture. & 6 & 0 & 1 & 1 \\
\hline Self-awareness of strengths/limitations. & 6 & 1 & 0 & 1 \\
\hline $\begin{array}{l}\text { Knowledge of differences in healthcare systems, beliefs about } \\
\text { health/sickness, etc. }\end{array}$ & 3 & 0 & 0 & 0 \\
\hline Manage projects. & 5 & 0 & 0 & 0 \\
\hline Interest in the field to be translated. & 6 & 0 & 0 & 0 \\
\hline Constant self-improvement. & 6 & 0 & 0 & 0 \\
\hline Common sense. & 6 & 0 & 0 & 0 \\
\hline
\end{tabular}

${ }^{1}$ Although we collected 189 responses, 22 of them were from translators who did not actually translate medical texts from English into Spanish, despite being categorised as working with 
that language pair in the professional directories and associations which we accessed. These 22 responses were excluded from the analysis in order to avoid distortion of the results.

${ }^{2}$ Appendix 1 includes the list of competences used.

${ }^{3}$ An extended version of these and other socio-professional traits can be found in Muñoz-Miquel (2016a).

${ }^{4}$ For further details on these and other differences between TLBs and TSBs, see Muñoz-Miquel (forthcoming).

${ }^{5}$ Note that the wording of these competences was condensed. The complete wording can be found in Appendix 1.

${ }^{6}$ This is due to the fact that the specialised courses, unlike the non-specialised ones, include course units devoted specifically to teaching basic medical concepts.

${ }^{7}$ It is important to note that information about the genres covered was obtained only from five out of the eight courses analysed. This result should therefore be treated with caution.

${ }^{8}$ A process of recontextualisation and reformulation of specialised terms aimed at making the concepts they designate relevant to and understandable by a lay audience. 